\title{
ЯМР-АНАЛИЗ СОСТАВА ЭФИРНЫХ МАСЕЛ ХВОИ ЕЛИ ОБЫКНОВЕННОЙ В ЗАВИСИМОСТИ ОТ АТМОСФЕРНОГО
} ЗАГРЯЗНЕНИЯ РАЙОНОВ МИНСКА

\author{
() Е.Д. Скаковский', Л.Ю. Тычинская ${ }^{1}$, О.А. Гайдукевич ${ }^{1}$, С.А. Ламоткин ${ }^{2 *}$, Д.С. Владыкина ${ }^{2}$, \\ С.В. Рыков ${ }^{3}$ \\ ${ }^{1}$ Институт фризико-органической химии НАН Беларуси, ул. Сурганова, 13, \\ Минск, 220072 (Республика Беларусь), e-mail: spektr@ifoch.bas-net.by \\ ${ }^{2}$ Белорусский государственный технологический университет, \\ ул. Свердлова, 13а, Минск, 220006 (Республика Беларусь) \\ ${ }^{3}$ Государственый университет управления, Рязанский проспект, 99, Москва, \\ 109542 (Россия)
}

\begin{abstract}
Методом гидродистилляции получено эфирное масло ели обыкновенной, произрастающей на территории с различным уровнем загрязнения. Методом спектроскопии ЯМР исследован компонентный состав масел. Установлена зависимость количественного содержания компонентов эфирного масла от условий произрастания ели обыкновенной.

Ключевые слова: ель обыкновенная, эфирное масло, терпены, спектры ЯМР.
\end{abstract}

\section{Введение}

В Минске сосредоточено значительное количество промышленных объектов, разнообразных не только по производимой продукции, но и по выбрасываемым в окружающую среду промышленным поллютантам, оказывающим неблагоприятное воздействие на экологическую систему в целом. Основные статические источники загрязнения расположены в центральной либо юго-восточной части города.

Однако, по данным экспертов, в Минске не существует «экологически чистых» районов, поскольку

Скаковский Евгений Доминикович - заведующий лабораторией спектроскопии, кандидат химических наук, тел.: +37517 284-17-05, e-mail: spektr@ifoch.bas-net.by

Тычинская Людмила Юльевна - ведущий научный сотрудник, кандидат химических наук, тел.: +37517 284-17-05, e-mail: spektr@ifoch.bas-net.by Гайдукевич Ольга Александровна - научный сотрудник, тел.: +37517 284-17-05, e-mail: spektr@ifoch.bas-net.by Ламоткин Сергей Александрович - доцент кафедры физико-химических методов сертификации продукции, кандидат химических наук, тел.: +37529 764-92-79, e-mail: jossby@ rambler.ru

Владыкина Дарья Сергеевна - магистр биологических наук, аспирант кафедры химической переработки древесины, тел.: +37529 557-69-48,

e-mail: laj-za@yandex.ru

Рыков Станислав Витальевич - доктор химических наук, профессор, тел.: (495) 371-98-33,

e-mail: inf@guu.ru
$85 \%$ загрязнений приходится на передвижные источники (автотранспорт) и только $15 \%$ - на стационарные источники (промышленные предприятия) [1].

Преобладающими являются западные, северозападные и юго-западные ветры, поэтому наблюдается перенос загрязненных воздушных масс со всего города в юго- и северо-восточную части Минска. Основные лесные массивы подходят к городу с восточной и северо-восточной стороны.

Леса города, занимая значительные площади (1083 га), выполняют важные рекреационные и средообразующие функции.

Важной задачей экологического мониторинга является контроль за состоянием лесов для информационного обеспечения принятия управленческих решений в области рационального природопользования, поддержания их устойчивости и функциональ-

\footnotetext{
* Автор, с которым следует вести переписку.
} 
ной эффективности экосистем, в сочетании с системой оповещения хозяйственных и директивных органов и прогнозирования состояния лесов.

Как показали исследования [2], именно листовая часть древесной зелени наиболее богата специфическими компонентами экстрактивных веществ с наиболее выраженными биологически активными свойствами. Специфичность листьев (хвои) заключается в особенностях биосинтеза вторичных метаболитов, в частности терпеноидов, не только в отдельных видах, но и в одном виде в зависимости от ареола произрастания и состояния окружающей среды. Наиболее восприимчив к особенностям места произрастания, генетически изменяется в части биосинтеза терпеноидов лист хвойных растений.

В настоящее время для контроля состава и качества эфирных масел преимущественно используются хроматографические методы $[3,4]$. Несмотря на их универсальность, для получения достоверных результатов при анализе сложных смесей в хроматографии зачастую необходимо использовать колонки с различными наполнителями и иметь в наличии индивидуальные компоненты анализируемых смесей, что увеличивает время анализа.

Спектроскопия ЯМР высокого разрешения в этом плане имеет значительные преимущества. Современные спектрометры обладают высокой чувствительностью, позволяют анализировать сложные составы на разных ядрах за достаточно небольшой промежуток времени, давая достоверные результаты [5].

Цель настоящей работы - анализ состава эфирных масел хвои ели обыкновенной в зависимости от атмосферного загрязнения районов Минска.

\section{Экспериментальная часть}

Объектами исследования служили 20-40-летние деревья ели обыкновенной, произрастающие на территории Минска, находящиеся под различным антропогенным воздействием. Образцы хвои отбирали в осенне-зимние месяцы, когда выход эфирного масла достигает максимального значения, а его состав стабилизируется [6].

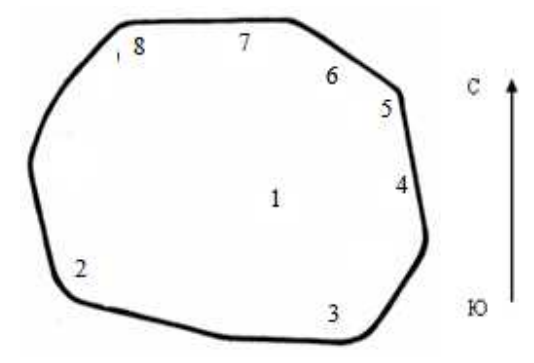

Рис. 1. Схема кольцевой дороги Минска

На рисунке 1 схематически приведена кольцевая дорога Минска с отметками мест отбора образцов. Образцы были отобраны с восьми участков: 1 - район тракторного завода, 2 - район мясокомбината, ул. Казинца, 3 - Чижовка, 4 - ул. Аранская, 5 район поселка Липки, 6 - Уручье, 7 - район реки Цна, 8 - район Минского моря. Во всех точках отбор образцов проводили с трех деревьев с целью получения усредненной пробы. В качестве эталона сравнения использовали древесную зелень, отобранную в Столбцовском районе внутри лесного массива в 20 км от города в стороне от господствующих ветров (образец 9).

Отобранную хвою отделяли от стволиков, измельчали до размера 35 мм, и из нее методом гидродистилляции отгоняли эфирное масло, а количественный выход определяли волюметрически. Общее количество выделенного масла зависело от места отбора образцов хвои, причем его содержание в образцах, собранных на севере Минска, было в 1,5 раза больше, чем в южных образцах.

Для анализа эфирные масла (0,1 мл) растворяли в 0,4 мл $\mathrm{CDCl}_{3}$. Спектры ЯМР записывали на спектрометре AVANCE-500 (Bruker) с рабочей частотой 500 и 126 МГц для ядер ${ }^{1} \mathrm{H}$ и ${ }^{13} \mathrm{C}$ соответственно. Запись проводили при температуре 293 К, в качестве внутреннего стандарта в ${ }^{1} \mathrm{H}$ спектрах использовали сигнал $\mathrm{CHCl}_{3}$ ( $\delta=7,27$ м.д.), ${ }^{13} \mathrm{C}$ - сигнал растворителя ( $\delta=77,7$ м.д.). Для записи ${ }^{1} \mathrm{H}$ ЯМР-спектров использовали $30^{\circ}$ импульс с релаксационной задержкой (RD) 5 с между импульсами, что обеспечивает количественное накопление сигналов. Анализ спектров показал, что практически все соединения легко идентифицируются по протонным спектрам в области частот 3,8-7,3 м.д., причем сигналы разных соединений не накладываются, что облегчает анализ. Для более полного отнесения компонентов смеси были записаны ${ }^{13} \mathrm{C}$ ЯМР-спектры в «рутинном» варианте записи: $45^{\circ}$ импульс, $\mathrm{RD}=7$ с. В спектрах дополнительно обнаружили сигналы камфоры и эвкалиптола. Их содержание было определено сравнением интегральных интенсивностей линий, относящихся к этим соединениям, и линий однотипных углеродных атомов (метиновых, метиленовых, метильных) других соединений, присутствующих в заметных количествах в эфирных мас- 
лах, количественное содержание которых было определено по ${ }^{1} \mathrm{H}$ ЯМР-спектрам. Такая процедура обеспечивает получение достоверных результатов, поскольку сравниваются средние значения интегральных интенсивностей многих сигналов.

Сравнение полученных методом ЯМР данных с результатами ГЖХ-анализа показало их хорошую согласованность в пределах относительной ошибки измерения.

Для отнесения сигналов в спектрах использовали методики корреляционной спектроскопии COSY45, NOESY, HSQC и HMBC.

Все экспериментальные данные получены и обработаны с использованием пакета программ XWINNMR 3.5.

Для идентификации и количественного определения содержания компонентов эфирных масел были записаны спектры различных терпеновых соединений, 14 из которых присутствовали в заметных количествах в исследуемых образцах и были нами проанализированы.

Поскольку изученные соединения являются многоспиновыми системами и имеют достаточно сложные спектры ЯМР, было сделано полное отнесение сигналов в спектрах. В таблицах 1 и 2 приведены химические сдвиги ${ }^{1} \mathrm{H}$ и ${ }^{13} \mathrm{C}$ ЯМР идентифицированных терпенов. Литературные данные по химическим сдвигам ${ }^{1} \mathrm{H}$ и ${ }^{13} \mathrm{C}$ ЯМР для некоторых соединений $[7,8]$ хорошо согласуются с нашими результатами.

Таблица 1. Химические сдвиги ${ }^{1} \mathrm{H}(\delta$, м.д.) компонентов эфирных масел хвои ели обыкновенной

\begin{tabular}{|c|c|c|c|c|c|c|c|c|c|c|c|c|}
\hline \multirow{2}{*}{$\begin{array}{c}\text { Соеди- } \\
\text { нение }\end{array}$} & \multicolumn{12}{|c|}{ Номер атома углерода } \\
\hline & 1 & 2 & 3 & 4 & 5 & 6 & 7 & 8 & 9 & 10 & 11 & 12 \\
\hline $\mathrm{I}$ & & 7,13 & 7,15 & & 7,15 & 7,13 & 2,34 & 2,89 & 1,26 & 1,26 & & \\
\hline II & $\begin{array}{c}5,27 ; \\
5,08\end{array}$ & 6,40 & & 2,25 & 2,22 & 5,18 & & 1,64 & 1,73 & $\begin{array}{l}5,04 ; \\
5,03\end{array}$ & & \\
\hline III & & 6,16 & 5,76 & 2,08 & $\begin{array}{c}1,78 ; \\
1,41\end{array}$ & $\begin{array}{l}2,46 ; \\
2,31\end{array}$ & $\begin{array}{r}4,78 ; \\
4,76\end{array}$ & 1,67 & 0,93 & 0,94 & & \\
\hline IV & & 5,42 & $\begin{array}{c}2,08 ; \\
1,91\end{array}$ & 2,11 & $\begin{array}{c}1,81 ; \\
1,50\end{array}$ & $\begin{array}{c}2,05 ; \\
1,97\end{array}$ & 1,67 & & 4,73 & 1,75 & & \\
\hline $\mathrm{V}$ & 0,64 & $\begin{array}{c}2,36 ; \\
1,97\end{array}$ & & 5,26 & $\begin{array}{c}2,19 \\
1,81\end{array}$ & 0,74 & & 1,62 & 1,05 & 0,79 & & \\
\hline VI & 1,96 & & 5,20 & $\begin{array}{l}2,26 ; \\
2,19\end{array}$ & 2,10 & & $\begin{array}{r}2,37 ; \\
1,19\end{array}$ & 1,69 & 1,30 & 0,87 & & \\
\hline VII & & 4,82 & $\begin{array}{c}2,30 ; \\
0,91\end{array}$ & 1,62 & $\begin{array}{l}1,69 ; \\
1,19\end{array}$ & $\begin{array}{c}1,89 ; \\
1,25\end{array}$ & & 0,85 & 0,82 & 0,78 & & 2,01 \\
\hline VIII & 2,70 & & & 1,93 & $\begin{array}{l}1,73 ; \\
1,42\end{array}$ & $\begin{array}{l}1,67 ; \\
1,27\end{array}$ & $\begin{array}{l}1,72 ; \\
1,23\end{array}$ & 1,09 & 1,06 & $\begin{array}{l}4,75 ; \\
4,52\end{array}$ & & \\
\hline IX & 2,48 & & $\begin{array}{l}2,55 ; \\
2,27\end{array}$ & $\begin{array}{l}1,87 ; \\
1,84\end{array}$ & 2,00 & & $\begin{array}{c}2,34 \\
1,45\end{array}$ & $\begin{array}{l}4,65 ; \\
4,59\end{array}$ & 1,27 & 0,75 & & \\
\hline $\mathrm{X}$ & & 3,98 & $\begin{array}{c}2,25 \\
0,93\end{array}$ & 1,61 & $\begin{array}{l}1,71 ; \\
1,23\end{array}$ & $\begin{array}{l}1,88 ; \\
1,23\end{array}$ & & 0,85 & 0,84 & 0,83 & & \\
\hline $\mathrm{XI}$ & & & $\begin{array}{c}2,29 \\
1,78\end{array}$ & 2,03 & $\begin{array}{l}1,89 \\
1,29\end{array}$ & $\begin{array}{l}1,62 ; \\
1,34\end{array}$ & & 0,85 & 0,90 & 0,77 & & \\
\hline XII & $\begin{array}{c}5,14 ; \\
5,10\end{array}$ & 5,96 & & $\begin{array}{l}1,85 \\
1,75\end{array}$ & $\begin{array}{l}1,98 ; \\
1,95\end{array}$ & 5,08 & & 1,67 & 1,59 & 1,54 & & 2,01 \\
\hline XIII & & 5,24 & $\begin{array}{c}2,10 ; \\
1,86\end{array}$ & & $\begin{array}{c}1,58 ; \\
1,51\end{array}$ & $\begin{array}{c}2,10 \\
1,86\end{array}$ & 1,63 & 1,62 & 0,90 & 0,87 & & \\
\hline XIV & & $\begin{array}{c}1,58 ; \\
1,41\end{array}$ & $\begin{array}{l}1,93 \\
1,41\end{array}$ & 1,32 & $\begin{array}{l}1,93 \\
1,41\end{array}$ & $\begin{array}{l}1,58 \\
1,41\end{array}$ & 0,93 & & 1,15 & 1,15 & & \\
\hline
\end{tabular}

Таблица 2. Химические сдвиги ${ }^{13} \mathrm{C}(\delta$, м.д.) компонентов эфирных масел хвои ели обыкновенной

\begin{tabular}{c|c|c|c|c|c|c|c|c|c|c|c|c}
\hline Соеди- & \multicolumn{10}{c}{ Номер атома углерода } \\
\cline { 2 - 14 } нение & 1 & 2 & 3 & 4 & 5 & 6 & 7 & 8 & 9 & 10 & 11 & 12 \\
\hline I & 2 & 3 & 4 & 5 & 6 & 7 & 8 & 9 & 10 & 11 & 12 & 13 \\
\hline I & 135,8 & 129,7 & 126,9 & 146,5 & 126,9 & 129,7 & 21,6 & 34,4 & 24,8 & 24,8 & & \\
II & 113,7 & 139,7 & 146,8 & 32,1 & 27,4 & 124,8 & 132,4 & 26,4 & 18,4 & 116,3 & \\
III & 134,8 & 121,4 & 30,2 & 128,2 & 27,3 & 32,1 & 20,8 & 122,3 & 24,1 & 20,3 & \\
IV & 134,3 & 121,3 & 31,5 & 41,8 & 28,6 & 31,3 & 24,1 & 150,8 & 109,1 & 21,5 & & \\
V & 17,4 & 21,5 & 132,0 & 120,1 & 25,5 & 19,2 & 17,4 & 24,3 & 29,0 & 13,9 & & \\
VI & 47,7 & 145,2 & 116,7 & 32,2 & 41,4 & 38,7 & 32,0 & 23,7 & 27,1 & 21,5 & & \\
\hline
\end{tabular}


Окончание таблищы 2

\begin{tabular}{c|c|c|c|c|c|c|c|c|c|c|c|c}
\hline$I$ & 2 & 3 & 4 & 5 & 6 & 7 & 8 & 9 & 10 & 11 & 12 & 13 \\
\hline VII & 49,2 & 80,4 & 37,3 & 45,4 & 28,6 & 27,6 & 48,3 & 20,3 & 19,4 & 14,0 & 171,9 & 21,8 \\
VIII & 47,6 & 166,9 & 42,5 & 48,8 & 24,5 & 29,6 & 38,1 & 30,1 & 26,6 & 99,8 & & \\
IX & 52,5 & 152,7 & 24,3 & 24,3 & 41,1 & 41,3 & 27,6 & 106,7 & 26,8 & 22,5 & \\
X & 50,1 & 77,9 & 39,6 & 45,7 & 28,9 & 26,6 & 48,6 & 20,8 & 19,3 & 14,0 & \\
XI & 58,2 & 220,2 & 43,8 & 43,6 & 27,6 & 30,4 & 47,2 & 9,8 & 20,3 & 19,7 & & \\
XII & 113,7 & 142,5 & 83,5 & 40,4 & 24,3 & 124,5 & 132,4 & 26,3 & 18,2 & 23,0 & 170,6 & 22,8 \\
XIII & 134,3 & 119,0 & 35,0 & 72,2 & 31,4 & 27,6 & 23,8 & 37,3 & 17,4 & 17,3 & & \\
XIV & 74,1 & 32,0 & 23,3 & 33,4 & 23,3 & 32,0 & 28,1 & 70,2 & 29,4 & 29,4 & & \\
\hline
\end{tabular}

\section{Результаты и их обсужндение}

На рисунке 2 представлены структурные формулы и пронумерованы углеродные атомы основных компонентов эфирного масла хвои ели обыкновенной: пара-цимол (I), мирцен (II), $\beta$-фелландрен (III), лимонен (IV), $\Delta^{3}$-карен (V), $\alpha$-пинен (VI), борнилацетат (VII), камфен (VIII), $\beta$-пинен (IX), борнеол (X), камфора (XI), линалилацетат (XII), терпинен-4-ол (XIII), эвкалиптол (XIV).<smiles>Cc1ccc(C(C)C)cc1</smiles><smiles>C=CC(=C)CCC=C(C)C</smiles><smiles>C=C1C=CC(C(C)C)CC1</smiles><smiles>C=C(C)C1CC=C(C)CC1</smiles><smiles>CC1=CCC2C(C1)C2(C)C</smiles><smiles>CC1=CC2(C)CCC1(C)C2(C)C</smiles><smiles>CC(=O)OC1C2(C)C=CC1(C)C1(C)CC2C1(C)C</smiles><smiles>C=C1C2CCC(C2)C1(C)C</smiles><smiles>[X]C12CCC(C)(CC1C)C2(C)C</smiles><smiles>[X]C12CC3(C)C4(C)CC(C)(C1(C)C4O)C23C</smiles><smiles>CC12CC3CC(C)(C1=O)C(C)(C2)C3(C)C</smiles><smiles>C=CC(C)(CCC=C(C)C)OC(C)=O</smiles><smiles>CC1=CCC(O)(C(C)C)CC1</smiles><smiles>CC12CCC(C(C)(C)C#N)C(C1)O2</smiles>

Рис. 2. Структурные формулы основных компонентов эфирного масла хвои ели обыкновенной 
${ }^{1} \mathrm{H}$ ЯМР спектры растворов в $\mathrm{CDCl}_{3}$ эфирных масел показаны на рисунке 3: a - образец из Столбцовского района, б - образец из района мясокомбината №2. Из рисунка 3 видно, что спектрально образцы подобны, но сильно отличаются количественным содержанием компонентов. Интерпретацию спектров можно провести при помощи данных таблицы 1.

Однако применение только ${ }^{1} \mathrm{H}$ ЯМР спектроскопии в данном случае удобно при анализе терпеновых соединений, имеющих олефиновые протоны или первичные и вторичные спиртовые группы, а также ароматические протоны, поскольку в спектрах, относящихся к ним, линии не перекрываются. Для насыщенных соединений, кетонов, оксидов (например камфоры и эвкалиптола) целесообразно использовать запись спектров на ядрах ${ }^{13} \mathrm{C}$ ЯМР.
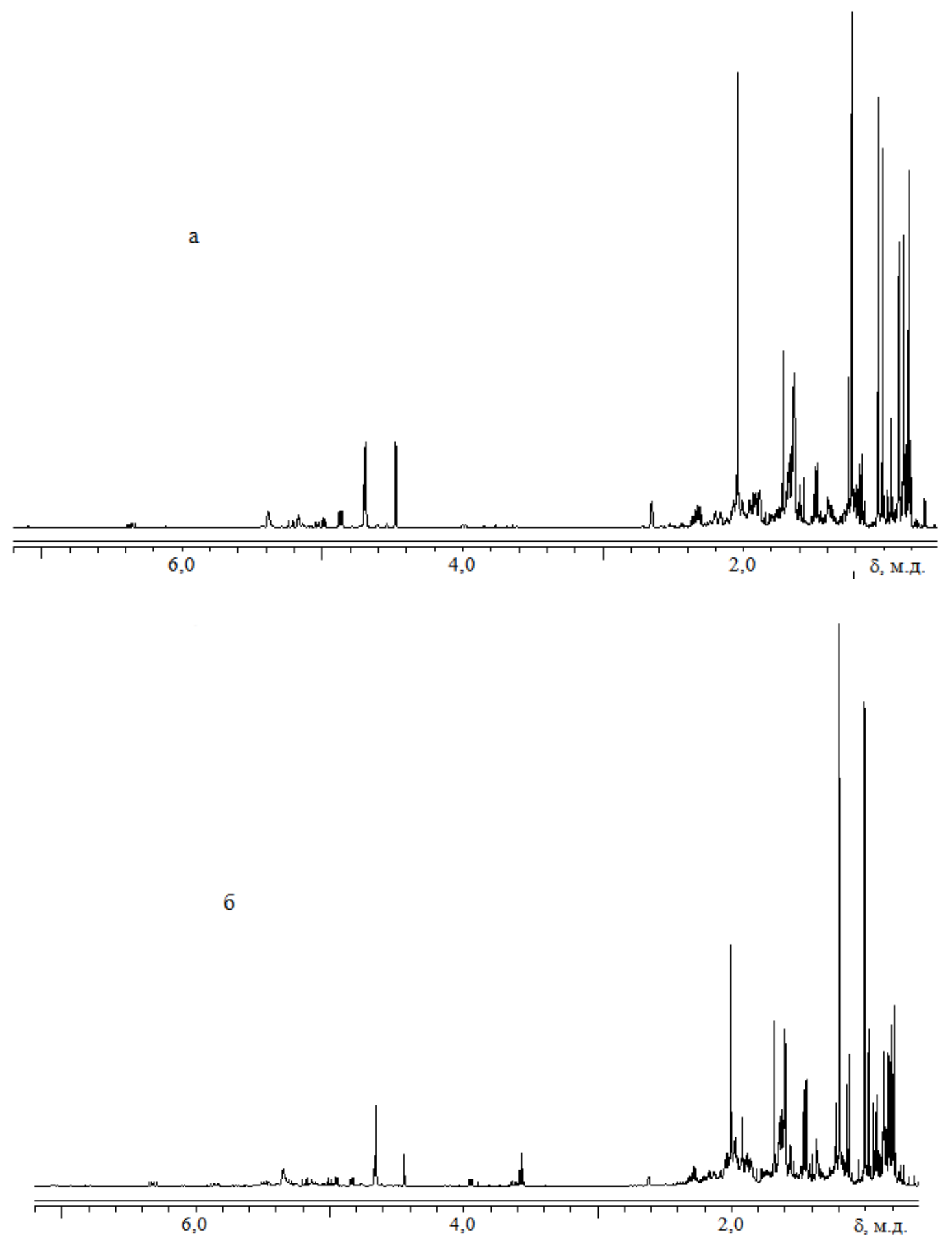

Рис. 3. ${ }^{1} \mathrm{H}$ ЯМР спектры растворов в $\mathrm{CDCl}_{3}$ эфирных масел ели обыкновенной: а - образец №9 из Столбцовского района, б - образец №2 из района мясокомбината 
На рисунке 4 представлены ${ }^{13} \mathrm{C}$ ЯМР спектры растворов эфирных масел, протонные спектры которых приведены на рисунке 3. Спектры содержат большое количество линий, но они, как правило, проявляются индивидуально и приемлемы для анализа состава эфирных масел при помощи таблицы 2.

Состав эфирных масел приведен в таблице 3. Главными компонентами эфирных масел хвои ели обыкновенной являются: борнилацетат (VII), лимонен (IV), камфен (VIII), эвкалиптол (XIV), борнеол (X) и $\alpha$-пинен (VI). Их суммарное содержание составляет более 66\%. Таблица составлена таким образом, что возрастание порядкового номера образца приблизительно соответствует более «чистому» району, т.е. снижению содержания токсичных элементов $\mathrm{S}$ и $\mathrm{Pb}$ в хвое с 169,0 до 92,3 и 0,1866 до 0,0029 мг/100 г. а.с.д. соответственно [9].

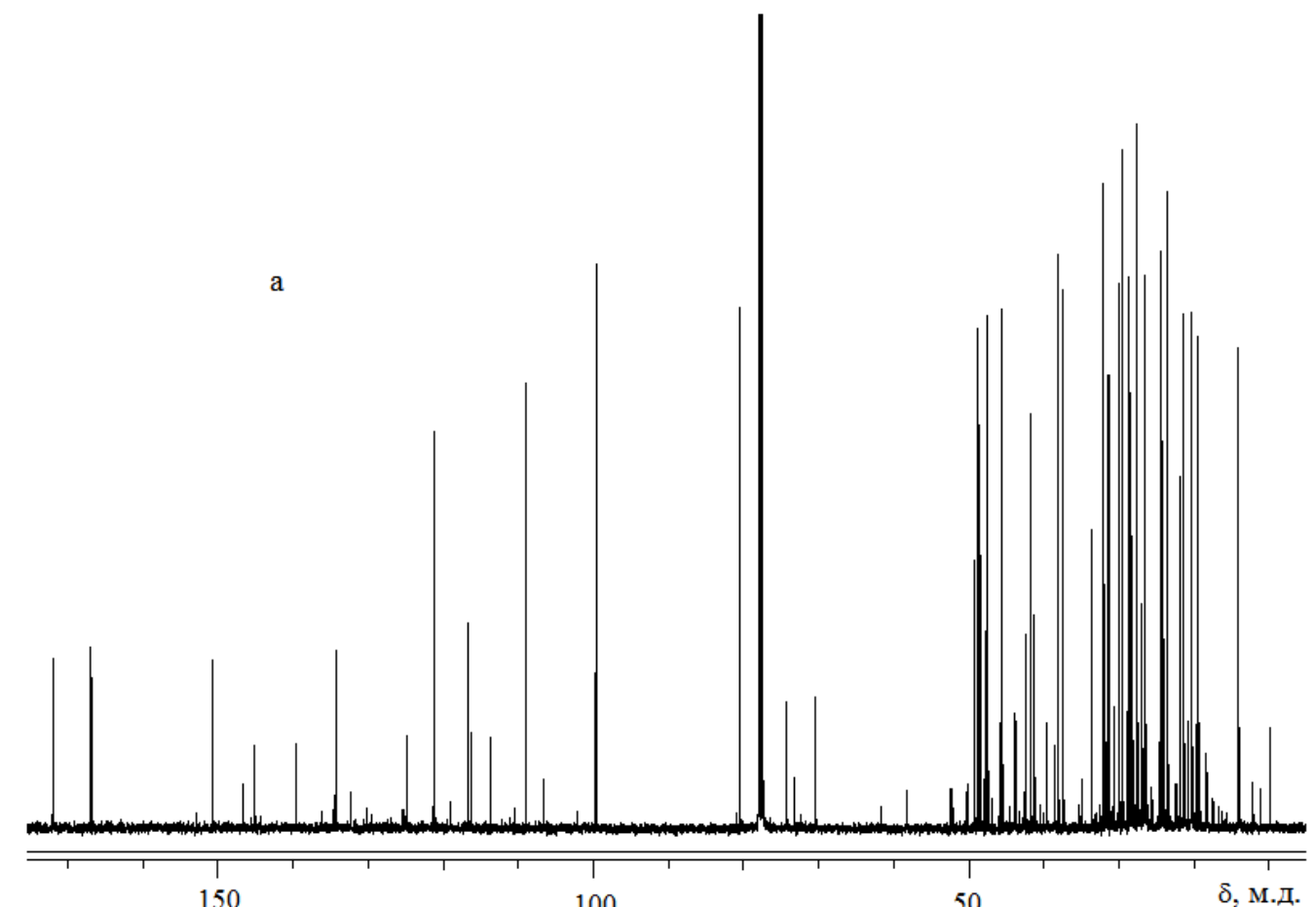

$\sigma$

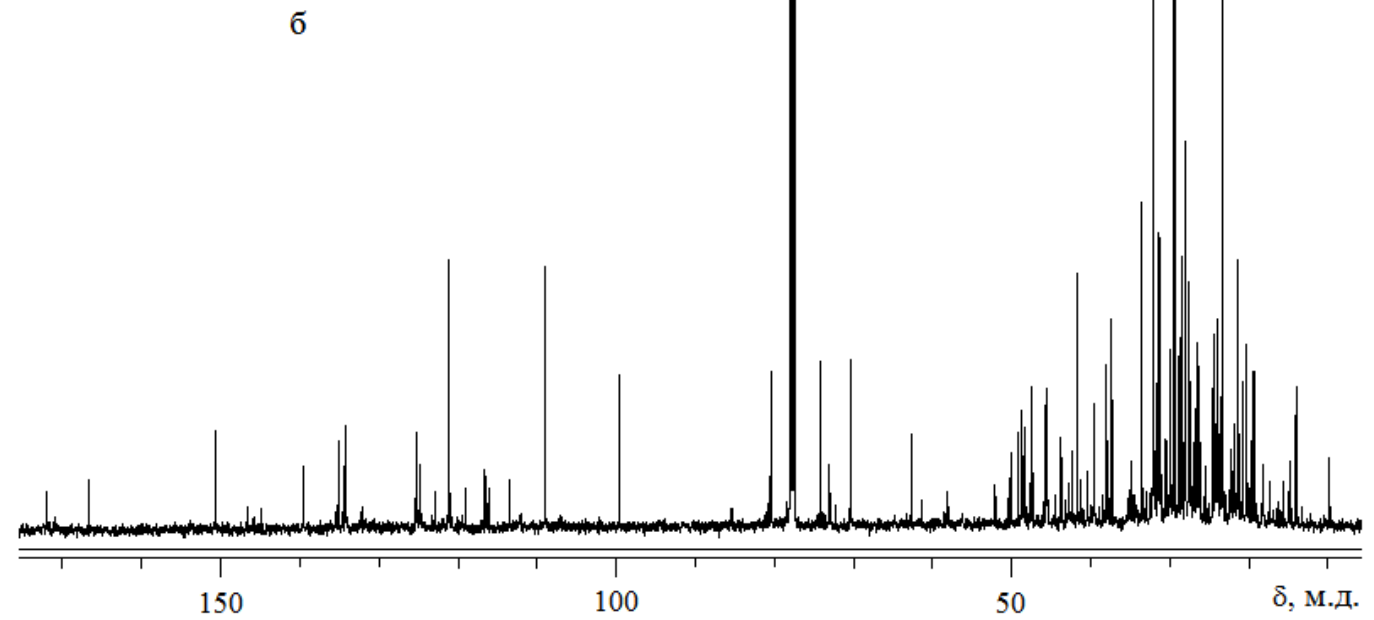

Рис. $4 .{ }^{13} \mathrm{C}$ ЯМР спектры растворов в $\mathrm{CDCl}_{3}$ эфирных масел ели обыкновенной: а - образец №9 из Столбцовского района, б - образец №2 из района мясокомбината 
Таблица 3. Состав эфирных масел хвои ели обыкновенной

\begin{tabular}{c|c|c|c|c|c|c|c|c|c}
\hline \multirow{2}{*}{$\begin{array}{c}\text { Соеди- } \\
\text { нение }\end{array}$} & \multicolumn{7}{c}{ Содержание, мольные \% } \\
\cline { 2 - 9 } & 1 & 2 & 3 & 4 & 5 & 6 & 7 & 8 & 9 \\
\hline I & 0,3 & 0,2 & 0,3 & 0,1 & 0,3 & 0,1 & 0,2 & 0,2 & 0,2 \\
II & 3,9 & 4,4 & 4,7 & 0,8 & 2,8 & 1,7 & 3,3 & 3,0 & 3,6 \\
III & 0,7 & 0,4 & 0,9 & 0,1 & 0,2 & 1,3 & 0,5 & 0,3 & 0,8 \\
IV & 15,5 & 19,2 & 12,9 & 7,8 & 17,4 & 5,2 & 16,9 & 16,1 & 17,0 \\
V & 0,6 & 1,0 & 0,7 & 0,4 & 0,5 & 1,7 & 0,6 & 0,5 & 0,1 \\
VI & 7,8 & 4,3 & 4,1 & 4,9 & 7,3 & 5,8 & 6,8 & 6,7 & 8,8 \\
VII & 10,8 & 11,1 & 18,3 & 44,3 & 25,4 & 39,2 & 16,7 & 22,2 & 17,8 \\
VIII & 16,5 & 10,4 & 9,7 & 11,2 & 16,0 & 7,1 & 12,0 & 12,6 & 19,6 \\
IX & 1,4 & 0,6 & 1,5 & 1,1 & 1,0 & 0,8 & 1,3 & 1,2 & 2,1 \\
X & 5,8 & 10,0 & 6,6 & 8,8 & 8,3 & 12,5 & 7,8 & 7,8 & 3,2 \\
XI & 6,1 & 5,0 & 2,0 & 1,7 & 3,0 & 4,2 & 5,7 & 1,9 & 2,7 \\
XII & 1,1 & 2,1 & 1,9 & 0,9 & 0,2 & 2,5 & 1,1 & 1,2 & 0,5 \\
XIII & 1,4 & 3,1 & 1,9 & 0,5 & 0,5 & 0,5 & 1,0 & 1,6 & 0,9 \\
XIV & 16,3 & 11,2 & 17,3 & 2,6 & 8,0 & 4,0 & 13,0 & 9,8 & 10,8 \\
\hline
\end{tabular}

Анализ таблицы показывает, что не наблюдается четких корреляций между порядковым номером образца и содержанием компонентов. Возможно, это связано с недостаточным количеством деревьев, взятых для получения усредненных проб. Кроме того, полученные результаты, вероятно, подтверждают мнение экспертов, что в Минске не существует «экологически чистых» районов.

Отметим, однако, определенную тенденцию в содержании некоторых компонентов эфирного масла. Так, содержание $\alpha$-пинена (VI) и камфена (VIII) ниже в образцах с более загрязненных территорий, а доля лимонена (IV), напротив, возрастает. Это можно объяснить тем, что увеличение техногенной нагрузки для ели обыкновенной ингибирует протекание реакций образования VI и VIII и смещает направление биосинтеза в сторону IV [10].

\section{Заключение}

Анализ состава эфирного масла хвои ели обыкновенной из различных районов Минска показал, что метод ЯМР можно использовать для получения достоверных результатов при определении количественного состава эфирных масел и экологического мониторинга территории.

\section{Список литературы}

1. Экологический обзор города Минска. [Электронный pecypc]. URL: http://www.vivainvest.by/files/ kologicheskij_obzor_g_minska_gotovyj.pdf

2. Рощин В.И. Состав экстрактивных веществ древесной зелени некоторых хвойных и новые направления их использования // Химия и использование экстрактивных веществ дерева: сб. тез. 3 Всерос. научно-техн. конфер. Горький, 1990. С. 6-7.

3. Хейфтман Э. Хроматография. М., 1986. С. 229-250.

4. Владыкина Д.С., Ламоткин С.А., Саморядов А.В. Хроматографический анализ состава эфирных масел ели в условиях техногенного загрязнения г. Минска // Труды БГТУ. Cер. IV. 2010. Вып. XVIII. С. 26-30.

5. Скаковский Е.Д., Ламоткин С.А., Шпак С.И., Тычинская Л.Ю., Гайдукевич О.А., Ламоткин А.И. Применение спектроскопии ЯМР для анализа состава эфирного масла хвои сосны // Журнал прикладной спектроскопии. 2006. Т. 73, №2. С. 246-249.

6. Степень Р.А. Экологическая и ресурсная значимость летучих терпенов сосняков средней Сибири // Химия растительного сырья. 1999. №2. С. 125-129.

7. RIO-DB provides research information of AIST. URL: http://riodb.ibase.aist.go.jp/riohomee.html.

8. nmrshiftdb2 - open nmr database on the web. URL: http://nmrshiftdb.nmr.uni-koeln.de/portal/plane0/portal/plane0/home

9. Shpak S.I., Lamotkin S.A., Lamotkin A.I. Chemical composition of Pinus silvestris essential oil from contaminated areas // Chemistry of Natural Compounds. 2007. V. 43. №1. Pp. 55-58.

10. Племенков В.В. Химия изопреноидов. Барнаул; Казань; Калининград, 2007. С. 18-38.

Поступило в редакцию 18 мая 2012 2.

После переработки 30 января 2013 г. 
Skakovsky E.D. ${ }^{l}$, Tychinskaya L.Y. ${ }^{l}$, Gaidukevich O.A. ${ }^{l}$, Lamotkin S.A. ${ }^{2}$, Vladykina D.S. ${ }^{2}$, Rykov S.V. ${ }^{3}$ NMR ANALYSIS OF THE COMPOSITION OF THE SPRUCE NEEDLES ESSENTIAL OILS, DEPENDING ON THE AIR POLLUTION OF VARIOUS DISTRICT IN MINSK

${ }^{1}$ Institute of Physical Organic Chemistry, National Academy of Sciences, ul. Surganova, 13, Minsk, 220072 (Republic of Belarus), e-mail: spektr@ifoch.bas-net.by

${ }^{2}$ Belarusian State Technological University, ul. Sverdlova, 13a, 2. Minsk, 220006 (Republic of Belarus)

${ }^{3}$ State University of Management, Riazanskii prospekt, 99, Moscow, 109542 (Russua)

Spruce essential oil from samples, growing in areas with different levels of pollution was obtained by hydrodistillation. The componential structure of the oils was studied by NMR spectroscopy. The dependence of the quantitative content of essential oil components on growth conditions was received.

Keywords: common spruce, essential oil, terpenes, NMR spectroscopy.

\section{References}

1. Ekologicheskii obzor goroda Minska. [Ecological overview of the city of Minsk]. URL: http://www.vivainvest.by/files/kologicheskij_obzor_g_minska_gotovyj.pdf. (in Russ.).

2. Roshchin V.I. Khimiia i ispol'zovanie ekstraktivnykh veshchestv dereva: sb. tez. 3 Vseros. nauchno-tekhn. konfer. [Chemistry and the use of wood extractives: Book of Abstracts 3 All-Russian Scientific and Technical Conference]. Gor'kii, 1990. C. 6-7. (in Russ.).

3. Kheiftman E. Khromatografiia. [Chromatography]. Moscow, 1986, pp. 229-250. (in Russ.).

4. Vladykina D.S., Lamotkin S.A., Samoriadov A.V. Trudy BGTU, Ser. IV, 2010, no. XVIII. pp. 26-30. (in Russ.).

5. Skakovskii E.D., Lamotkin S.A., Shpak S.I., Tychinskaia L.Iu., Gaidukevich O.A., Lamotkin A.I. Zhurnal prikladnoi spektroskopii, 2006, vol. 73, no. 2, pp. 246-249. (in Russ.).

6. Stepen' R.A. Khimiia rastitel'nogo syr'ia, 1999, no. 2, pp. 125-129. (in Russ.).

7. RIO-DB provides research information of AIST. URL: http://riodb.ibase.aist.go.jp/riohomee.html.

8. Nmrshiftdb2 - open nmr database on the web. URL: http://nmrshiftdb.nmr.uni-koeln.de/portal/plane0/portal/plane0/home

9. Shpak S.I., Lamotkin S.A., Lamotkin A.I. Chemistry of Natural Compounds, 2007, vol. 43, no. 1, pp. 55-58.

10. Plemenkov V.V. Khimiia izoprenoidov. [Chemistry isoprenoid]. Barnaul-Kazan-Kaliningrad, 2007. pp. 18-38. (in Russ.).

Received May 18, 2012

Revised January 30, 2013

\footnotetext{
* Corresponding author.
} 